\title{
LA HERENCIA DE DARWIN Y EL PROBLEMA DE LA JUSTIFICACIÓN FILOSÓFICO-JURÍDICA DE LA DIGNIDAD HUMANA
}

\author{
Atahualpa Fernandez ${ }^{\odot}$ \\ Universitat de les Illes Balears
}

\begin{abstract}
Resumen.- Este estudio tiene como objetivo examinar el problema de la justificación filosóficojurídica de la dignidad humana desde una perspectiva naturalista acerca de la naturaleza humana como "objeto" de investigación empírica. Un concepto de dignidad humana desarrollado a partir de un enfoque naturalista permite enfrentarse, de forma real y factible, a la evidencia de que la naturaleza humana no sólo genera sino que guía y pone límites al conjunto institucional y normativo que establece sus condiciones de posibilidad.
\end{abstract}

Palabras clave.- Derecho, dignidad humana, darwinismo, naturaleza humana, sentimiento moral

Abstract.- This study aims to examine the problem of philosophical justification and the legal theory of human dignity since a naturalistic perspective about human nature as "object" of empirical research. A concept of human dignity developed from a naturalistic approach allows to be opposed, a real and practicable form, to the evidence that human nature not only generates but guides and sets limits to the institutional and normative set that regulates its conditions of possibility.

Keywords.- Law, human dignity, darwinism, human nature, moral sense

Por "dignidad" se entiende, en el contexto filosófico-jurídico, una determinada condición del ser humano que le distingue de cualquier otro animal y fundamenta ciertos derechos indiscutibles al estilo de tener que ser considerado, a la manera kantiana, como un fin en sí mismo y no como medio para otros propósitos. Ése es el punto de partida que nos lega Kant en su Metafísica de las costumbres (Kant, 1785) al sostener que el humano no tiene precio sino dignidad, valor intrínseco.

Un planteamiento así, referido a un "ser humano" genérico, sin distinción de sexo, edad, clase social, etnia, saber, nacionalidad u oficio, parece llevar de manera necesaria a la condición común de cualquier persona, a la naturaleza biológica humana derivada de los rasgos de la especie. Pero el proceso de construcción del concepto, antes y después de Kant, ha conducido en realidad a la meta opuesta: la de negar viabilidad alguna a las características biológicas del ser humano siempre que se trate de llevar a cabo la justificación filosóficojurídica de la dignidad.

\footnotetext{
- Profesor Colaborador Honorífico e Investigador de la Universitat de les llles Balears/España/Laboratório de Sistemática Humana/ Evocog. Grupo de Cognición y Evolución humana/Unidad Asociada al IFISC (CSIC-UIB)/Instituto de Física Interdisciplinar y Sistemas Complejos/UIB. Fiscal del Ministerio Fiscal de Brasil (Ministério Público da União /Brasil).
} 
El problema es que la habitual concepción de la dignidad filosófico-jurídica, sin ninguna referencia a las mejores teorías y evidencias científicas a disposición acerca de la naturaleza humana, no significa nada. Decir que alguien es digno, sin más, es dejar la frase incompleta o, lo que es lo mismo, equivale a no decir nada. Sin embargo, palabras como "dignidad", aunque privada de contenido semántico, continúan a provocar secreción de adrenalina en determinados filósofos y juristas propensos a una retórica anticientífica, autocomplaciente o pretendidamente muy "científica", dominada, sobre todo, por un positivismo de "reglas y principios", un sociologismo, un iusnaturalismo con su peculiar ontología sustancialista y/o por el modismo de las más recientes teorías sobre los derechos humanos y fundamentales. Mientras algunos ( los postmodernos) huyen de la realidad social, científica y política con delirantes imposturas ("todo es texto" y majaderías parecidas), los otros ( los "científicos", los "puristas" y los "filósofos de los derechos humanos") huyen de la realidad social e científica construyendo triviales pseudomodelos teóricos que no son a menudo sino grotescas parodias argumentativas sin cualquier escrutinio empírico mínimamente serio, sino carentes de la menor autoconsciencia respecto a la realidad biológica que nos constituye y a los hondos problemas filosóficos y neuropsicológicos que entraña cualquier teoría con rasgos de seriedad e coherencia acerca de la dignidad humana. Es decir, deifican el mundo de la moral (como sistema de signos y representaciones arbitrarios que existen independientemente de la condición humana) y exageran su consistencia ontológica al margen de una naturaleza humana como objeto de investigación empírica.

Además, los buenos argumentos basados exclusivamente en la mera contemplación teórica indican de manera muy clara los riesgos que se corre cuando utilizamos criterios de abstracción y universalización de la dignidad que no procede de una consideración contrastada de la naturaleza biológica humana $^{1}$. Y la Historia nos muestra el hecho desgraciado de que los intentos morales más fuertes de mejorar la sociedad humana y ejecutados en nombre de la preservación de una dignidad humana abstracta han llevado en ocasiones a todo un catálogo de propuestas y situaciones monstruosas, acompañados de la perversa incapacidad de indignarse ante la injusticia y de conmoverse ante el sufrimiento desnecesario.

En resumen, teorizar sobre la dignidad humana despreciando la necesidad de se llevar en consideración las aportaciones procedentes de las ciencias

\footnotetext{
${ }^{1}$ Un buen ejemplo de esos riesgos puede ser el siguiente: la filosofía de la Grecia clásica —la Etica a Nicomaco, por ejemplo-, atribuyó la dignidad no a cualquier ser humano sino sólo a una parte reducida de nuestros congéneres, a aquellos pocos a los que cabía considerar como miembros de la polis. Es esclarecedor, a tal respecto, el capitulo $8^{\circ}$ de la ética nicomáquea que Aristóteles dedica a la amistad. En sentido estricto, Aristóteles no estaría trasgrediendo la condición universal humana. Lo que se hace por medio de esa reducción es identificar "ser humano" y "miembro de la polis", equiparando, por ejemplo, los esclavos a los no-humanos. Si los esclavos no se consideran humanos, tampoco estamos negándoles valor moral alguno; se encuentran en la misma situación en que quedaría cualquier simio u otro animal. De hecho, pues, el carácter universal se mantiene: el error es de tipo antropológico, al constatar lo que es y lo que no es un Homo sapiens, y no filosófico-jurídico. El mismo error, por cierto, que se cometió en los Estados Unidos cuando la Convención de Filadelfia discutió en 1787 si los esclavos debían ser considerados o no personas. El llamado "Compromiso de los 3/5" estableció que, a algunos efectos, un esclavo era tres quintas partes de una persona.
} 
adyacentes desde una perspectiva interdisciplinar, es una estafa (Stamos, 2009). O bien optamos por considerar que la ciencia jurídica es un ámbito gnoseológico autocontenido que no requiere hacer explícitos los principios ni la metodología de investigación procedentes de otras disciplinas (una suerte de reino causalmente aislado), de modo que no nos queda otra salida que la vía de exploración hermenéutica y especulativa; 0 bien consideramos epistémicamente irrenunciable la necesidad de encontrar explicaciones empíricamente contrastables y consideramos, además, que el verdadero conocimiento de lo humano consiste en descifrar la red de conexiones causales entre las dimensiones natural y cultural, a partir de un programa constructivo, interdisciplinario y cargado de responsabilidad acerca de la naturaleza humana.

Salir de la magia o del misterio en dirección a una mayor claridad de las ciencias hará con que nos adentremos en el sendero que lleva a entender con mayor precisión en que consiste realmente la verdadera dignidad del ser humano.

\section{El legado intelectual de Darwin}

Charles Darwin integró al hombre en el mundo animal y transformó para siempre el modo de pensar de todas las personas ilustradas del planeta. La herencia que recibimos de Darwin puede ser mensurada, fácilmente, considerándose la influencia actual de la teoría de la evolución. Que el hombre es un animal, una parte indistinguible de la naturaleza orgánica, edificado de acuerdo con los mismos principios genéticos que cualquier otro ser vivo, no sólo es una evidencia científica indiscutible, sino también un lugar común en la literatura científico-natural, social y humanística. Pero Darwin no nos enseño sólo el camino de la comprensión de la evolución de los seres vivos. Su teoría de la evolución por selección natural sirve también para comprender por qué nos comportamos de forma moral y lo que es la ética. De hecho, es precisamente el programa naturalista iniciado por Charles Darwin en la segunda mitad del siglo XIX con su teoría de la evolución que puede proporcionarnos argumentos a favor de la existencia de universales éticos, de eses que John Rawls consideraba principios esenciales de la justicia.

Sin embargo, la introducción del saber acerca de nuestra naturaleza biológica en el discurso de las humanidades y las ciencias sociales resultó (y todavía resulta) compleja e incómoda - para no decir imposible -, en la medida en que su legitimidad se concibe como limitada a los territorios ajenos a la influencia de la cultura. Naturaleza y cultura han convivido como reinos separados durante siglos, al amparo de los dualismos legitimadores de sus orígenes míticos. De ahí que todavía sorprenda a muchos el argumento de que resulta inaceptable toda y cualquier ciencia social normativa que no tenga en cuenta el sustrato animal de la sociedad humana, es decir, de que los hombres viven en sociedad no porque son hombres (o ángeles), sino porque son animales.

De todos modos, lo cierto es que desde una perspectiva más científica que humanista, filosofamos después de Darwin. Sabemos que descendemos de aquellos primeros simios que comenzaran a caminar sobre dos patas. 
Sabemos que existe algo que denominamos naturaleza humana, con cualidades físicas y una serie de predisposiciones genéticas para desarrollarnos adecuadamente en nuestro entorno. Sabemos que algunas propiedades fijas de la mente son innatas, que todos los seres humanos poseen ciertas destrezas y habilidades de las que carecen otros animales, y que todo eso conforma la condición humana. Sabemos que la materia prima de la cultura son representaciones mentales, personales y compartidas y que toda representación es, en última instancia, obra de nuestro cerebro (un irrefutable producto de la evolución por selección natural, el resultado vivo de un largo proceso filogenético y capaz de vivir en un universo no percibido); es decir, que nada ocurre, ni nada existe en el mundo humano que no sea percibido, filtrado, elaborado y construido por nuestro cerebro (lo que incluí como pensamos, interpretamos, sentimos, creamos y modificamos nuestras representaciones ético-jurídicas). En realidad, comienza a acumularse evidencias, desarrolladas en campos disciplinares muy variados, sugiriendo la existencia de un "instinto moral", una facultad moral equipada con propiedades universales de la mente humana que restringe el ámbito de la variación cultural, que guía inconscientemente nuestros juicios de valor y que permite desarrollar una reducida gama de sistemas morales concretos.

Por primera vez los avances de las investigaciones procedentes de las ciencias de la vida y de la mente ofrecen líneas de convergencia capaces de situar la reflexión humanística y científico-social sobre una concepción de la naturaleza humana como objeto de investigación empírico-científica y no más fundada o construida a partir de mera especulación metafísica. Hoy, más que nunca, se impone la convicción de que ninguna filosofía o teoría social normativa, por poco seria que sea, puede permanecer encerrada o aislada en una torre de marfil fingiendo ignorar los resultados de los descubrimientos procedentes de los nuevos campos de investigación científica que trabajan para extender un puente entre la naturaleza y la sociedad, la biología y la cultura, en forma de una explicación científica de la mente, del cerebro y de la naturaleza humana.

Es ésta la clave para entender que la comprensión científica de la naturaleza humana, a nuestro juicio, es de una importancia crucial para fundamentar y solventar, a partir de la construcción conjunta de alternativas reales y factibles, los problemas que conciernen de manera profunda a la dignidad humana.

\section{Enunciados descriptivos y enunciados valorativos}

Como es sabido, la falacia naturalista - atribuida en su formulación inicial a David Hume - tilda de error lógico el fundamentar en enunciados de hecho cualquier descripción de la naturaleza biológica humana- las proposiciones morales -es decir, tanto el sentido profundo filosófico-jurídico de la dignidad como sus contenidos prácticos (por ejemplo, Muguerza, 1977). Como consecuencia de esa negativa a tener en cuenta enunciados descriptivos de cariz biológico, la operación de análisis de los valores morales que termina imponiendo conceptos universales como el de "derechos humanos" se realiza en términos de sociedad, por contraposición a naturaleza. 
Los resultados de un planteamiento así son harto conocidos. Abundan las propuestas que, desde la ciencia jurídica o la filosofía, han ofrecido conceptos, criterios y principios destinados a establecer una definición acerca de lo que es la dignidad humana y hacia dónde conduce. En la mayor parte de ellas, la idea que subyace a las teorías disponibles presenta al ser humano como poseedor de una dignidad a la que cabría llamar trascendental, ajena por completo a su historia evolutiva. El ser humano se considera como una persona racional y moral que, por lo que hace al menos a esa doble condición, resulta autónoma e independiente de las leyes de la naturaleza. Por añadidura, tal condición de autonomía es exclusiva. De manera implícita $-\mathrm{y}$ a menudo explícitamentese postula la existencia de una gran diferencia cualitativa entre los humanos y los demás seres vivientes, un plus humano derivado de la condición moral de nuestra especie. En realidad se trata de distintas caras de la misma moneda: son las mismas razones las que sustentan que se es autónomo y libre y que se tiene una superioridad sobre cualquier otro ser.

Pese a que esa idea forma parte, como decimos, de la mayor parte de las propuestas, cuando los operadores jurídicos abordan el estudio de la dignidad humana suelen sostener la presencia de diversos tipos de explicaciones como las sociológicas, antropológicas, normativas o axiológicas-, ajustadas a las perspectivas de cada una de las respectivas disciplinas. Es decir, salvo que se apele a valores últimos de carácter cuasireligioso, no se considera siquiera la posibilidad de que exista una sola clase de explicación para justificar el valor de la dignidad en su proyección ético-jurídica.

Pero tal explicación unitaria de base existe. Desde el punto de vista teórico, es posible imaginar una fundamentación que atraviese las escalas del espacio, del tiempo y de la complejidad, uniendo los hechos aparentemente irreconciliables de lo social y lo natural. Basta, para ello, con entender:

1. que parte de nuestra naturaleza - lo que cabría llamar en términos técnicos "rasgos primitivos" - ha aparecido gracias a la evolución por selección natural millones de años antes de que apareciera nuestra especie

2. que otras características exclusivas de los humanos -los "rasgos derivados" - se añadieron o perfeccionaron a lo largo de nuestra historia evolutiva separada, dentro del linaje que nos incluye a nosotros y a nuestros antecesores no compartidos con ningún simio.

3. que la hipótesis más razonable sostiene que las condiciones que corresponden a nuestra psicología moral, aquellas que sustentan la dignidad humana, deben darse por moldeadas como rasgos o bien primitivos 0 derivados. En caso de negarlo, es preciso ofrecer explicaciones creíbles, alejadas de la invocación de valores supremos, acerca de cómo podrían haber aparecido.

4. que sólo la comparación con las actitudes y valoraciones morales de otros seres pueden dar pistas acerca del carácter primitivo o derivado de la condición moral y la dignidad humana.

El propósito de este artículo es el de indicar los principales rasgos de un programa así de naturalización de la dignidad. Eso no significa el intento de sustituir la condición social humana por su condición biológica. Dejando aparte los aspectos lógico-formales de la falacia naturalista —resueltos ya por Hare 
(Hare, 1979) - el mayor error de un concepto de dignidad ciudadana apartado de nuestra condición biológica como especie es el del uso de un planteamiento dualista cartesiano de res cogitans frente a res extensa. Por razones que vamos a abordar de inmediato, carece de sentido plantear la fundamentación moral en términos de "lo natural" frente a "lo social", ni de "lo innato" frente a "lo adquirido".

\section{El problema de la naturaleza humana}

Nadie ignora que el hombre es un ser cuya naturaleza es esencialmente social: un primate que nació para vivir en comunidad. Como los demás antropoides africanos, la naturaleza del ser humano es esencialmente social: nuestra condición es la de un primate que nació para vivir en comunidad. La expresión latina unus homo, nullus homo expresa bien esa naturaleza que nos caracteriza como especie social. La interpretación más común de ese hecho en términos de evolución por selección natural es la de entender que, para nuestros antepasados, representó una ventaja adaptativa la constitución de una vida socialmente organizada. El humano aislado, sin una comunidad social en la cual pueda plasmar su existencia — por no hablar de su dignidad-, no es tal. Hemos sido diseñados por la selección natural para desarrollarnos, aprender a vivir y prosperar en un entorno social, en el marco de las restricciones de un mundo natural. El fenómeno de la competencia lingüística pone muy bien de manifiesto esa integración de naturaleza y sociedad.

En el modelo presentado por Chomsky (Chomsky, 1966, 1968, 1980, 1985), etc.), la competencia lingüística es un rasgo innato que debe actualizarse mediante la pertenencia a una familia, a una tribu o a una sociedad. La capacidad humana para desarrollar un lenguaje no se consigue sin las señales fonético-semánticas procedentes de un grupo social.

Las consecuencias de esa suma de competencia y actuación-o, mejor dicho, de su integración complementaria- son importantes para entender la necesidad de desechar el dualismo. Por razones que tienen que ver con la aparición, hace cerca de 7 millones de años, del único rasgo derivado humano compartido por todo el conjunto de los homínidos, la bipedia, las caderas de los miembros de nuestro linaje se transforman. El incremento del volumen craneal en el genero Homo que se produce a medio camino en la evolución de la familia de los homínidos, a partir de 2,5 millones de años atrás, convierte en un problema el nacimiento de seres con cerebros cada vez más grandes cuyas madres tienen un canal pélvico estrecho. La solución que la selección natural impone es la de nacer con el cerebro muy poco desarrollado. Así que, durante su infancia, cada nuevo ser humano aumenta y completa su cerebro mediante un proceso que necesita de las señales procedentes del grupo para poder realizarse. No es sólo el lenguaje el que faltaría si un niño creciese alejado de cualquier grupo. Es el propio cerebro el que no podría madurar.

¿Y qué decir de otros elementos pertenecientes a nuestra constitución como individuos?

La hipótesis más razonable establece que la naturaleza humana y, consecuentemente, el sentido del yo, es en gran medida el resultado de una 
mezcla similar a la del caso del lenguaje: una amalgama en la que genes y neuronas por una parte, y experiencias, valores, aprendizajes e influencias procedentes de nuestra vida socio-cultural, por otra, confluyen para dar el resultado final de un individuo inseparable de la sociedad. Cuando se habla de dignidad y de sus efectos prácticos, es, pues, viable -e incluso exigible- el planteamiento de nuevos criterios para que los sectores del conocimiento propios del derecho sean revisados a la luz de los estudios provenientes de la ciencia cognitiva, de la neurociencia, de la genética del comportamiento, de la antropología, de la primatología y de la psicología entre otras disciplinas que buscan entender en que consiste nuestra naturaleza como especie.

Ese conjunto de ciencias puente, basadas todas ellas en la perspectiva doble individuo-sociedad, nos enseña que el comportamiento humano se origina a partir de la intercesión de nuestro sofisticado programa cognitivo de raíz filogenética con el entorno socio-cultural en que transcurre nuestra ontogénesis. También nos indica que las representaciones culturales deben ser vistas como algo que se sustenta en mecanismos propios de nuestra arquitectura cognitiva innata. La estructura y el funcionamiento de esos mecanismos regulan de qué modo las representaciones específicas se transmiten de un individuo a otro, distribuyéndose dentro de la comunidad como respuesta a condiciones sociales y ecológicas distintas. En síntesis, es la naturaleza humana la que impone constricciones significativas para la percepción, transmisión y almacenamiento discriminatorio de representaciones culturales, limitando las variaciones sociales y morales posibles.

A un nivel más profundo, la existencia de esos mecanismos también implica que existe en nuestra especie una considerable carga de contenido mental universal. Como sostienen las primeras intuiciones de Darwin acerca de la naturaleza humana (Darwin, 1871), hemos nacido con determinados instintos morales, en un marco en que la educación interviene para graduar los parámetros y guiarnos hacia la adquisición de sistemas morales y jurídicos particulares. Hay algo, pues, en el cerebro humano que nos permite adquirir un sistema de valores y principios ético-jurídicos y que permite sostener la existencia de universales morales en un sentido fuerte del término (Tugendhat, 1979; Hauser, 2006). Para ciertas cosas, por tanto, hay una sola moral universal.

Si es así, también habrá que aplicar al caso de los valores humanos más apreciados — justicia, libertad, autonomía, dignidad- la idea de que sólo a través del conocimiento de la mente, del cerebro y de la naturaleza humana, podemos tener la esperanza de hacer una contribución significativa a la compresión del ser humano y de la cultura por él producida (Zeki, 1993). No es posible comprender el sentido profundo de la dignidad humana sin abordar antes la complejidad de nuestra mente y del cerebro que la habilita y que la sostiene, un conjunto que gestiona y genera el sentido de la identidad y personalidad, la percepción del otro y la intuición de nuestra autonomía propia.

Pero, ¿existe de hecho una naturaleza humana capaz de hacer todo eso? Y, de ser así, ¿en qué consiste a los efectos de la manera como cabe entender la dignidad? ¿No podría ser que diera igual, que cualquier programa iusnaturalista, incluso de cariz religioso, se bastase para establecer el principio de igualdad y dignidad para todos los humanos? 
La respuesta es negativa. Cualquier concesión ideológica está amenazada de los errores producidos por el desconocimiento. La historia reciente indica bien que la condición humana, y sus atributos ligados a la posesión de valores, debe ser definida en términos antropológicos y no políticos ni religiosos. El proceso de expansión del "círculo moral" (Singer, 1981) pasa por devolver a los humanos su condición universal pero no termina ahí. Esclavos primero, pobres sin tierras más tarde, mujeres por último ganaron carta de naturaleza humana. ¿Dónde termina el proceso? ¿Qué dignidad tienen los niños, los enfermos, los disminuidos físicos y mentales? ¿Cuál es la dignidad de psicópatas y criminales? ¿Qué decir de los demás seres vivos? ¿Y de los que aún no han nacido? Las respuestas menos arriesgadas son las que puedan llegarnos gracias a esos enunciados descriptivos procedentes de las ciencias que la falacia naturalista quiso descalificar.

\section{El riesgo del determinismo}

A los efectos de lo que aquí interesa, la tarea más urgente e importante sería la de poder indicar qué universales éticos confluyen en la dignidad humana de la mano de la selección natural.

Conviene, antes de adentrarse por esos derroteros, entender de qué estamos hablando puesto que se corre el peligro de confundir las propuestas naturalistas. Algo así sucedió cuando la sociobiología, de la mano de Edward Wilson, propuso apartar la ética de la mano de los filósofos y situarla en la de los biólogos (Wilson, 1975). La obra posterior de Wilson está llena de propuestas filosóficas que se sostienen mal a la luz de los conocimientos científicos. Por ejemplo, al utilizar el comportamiento altruista de los insectos sociales como modelo para entender la moralidad humana, Wilson (Wilson, 1978) cometió el error de confundir lo que es probable que no sean sino una homoplasia —un rasgo sólo en apariencia similar, fijado por separado en dos linajes distintos sin relación genética entre ellos-, dándola por una plesiomorfia - un rasgo que se comparte porque lo fijó un antepasado común. En la medida en que el sistema altruista de termitas, hormigas, avispas y abejas está completamente determinado, cabe entender las barbaridades que se derivan de trasladar ese esquema a la ética humana.

¿Cuál es entonces, si hay alguno, el alcance de la determinación genética que preside la moralidad humana?

A estas alturas es pertinente llevar a cabo una precisión en el análisis de la conducta moral. La distinción entre motivo para actuar y criterio aplicado a cualquier acción a la hora de calificarla moralmente, es muy común en la literatura especializada anglosajona (Cela Conde, 1985) pero suele ser ignorada en el ámbito filosófico-jurídico ajeno a esa tradición. Cabe ignorarla si cualquier amago de fundamentación naturalista de la moral se desecha de antemano al considerarse determinista. Pero resulta tan necesario como obvio indicar ya que ese supuesto determinismo dista mucho de ligar de manera necesaria la posesión de ciertas características propias de la especie y toda conducta relacionada con el juicio moral. Ningún sujeto tiene por qué ajustarse, a la hora de comportarse, a sus creencias acerca del bien y del mal. Es del 
todo posible creer, por ejemplo, que uno está obligado a prestar ayuda a una persona asaltada por maleantes y, por miedo a las consecuencias, abstenerse de hacerlo.

De no ser así, de actuar siempre en consonancia con nuestros criterios éticos, no existiría el remordimiento. Pues bien, los universales que se pueden deducir de la naturaleza humana se refieren tanto a las motivaciones como a la estructura del juicio moral, a la manera como se plantea el juicio ético, y no a su contenido (Cela Conde, 1986; Ayala, 1987). La condición de ser moral implica no el seguir ciertas reglas, sino el utilizarlas como baremo para juzgar conductas. Darwin (1871) utilizó el concepto ilustrado de moral sense para describir ese rasgo humano distintivo, y nos lo atribuyó en exclusiva. Si bien otros animales podrían llegar, con la evolución de sus facultades cognitivas, a alcanzarlo, ninguno dispone de él. Somos sentimiento moral por naturaleza y, gracias a él, valoramos, apreciamos y llevamos a cabo conductas que corresponden a la posesión de ciertos valores compartidos. Pero no lo hacemos de manera automática.

Hasta aquí, pocos filósofos y juristas dispuestos a discutir los términos naturalistas podrían encontrar argumento alguno para desechar el planteamiento darwiniano. Carece de riesgo, en términos de posible falacia, el decir que nuestra naturaleza nos lleva a juzgar pero no indica las pautas del juicio. De hecho, cabría considerarlo una trivialidad ¿de qué, si no es así, estaríamos hablando? ¿Qué le quedaría a la ética si no compartiese nuestra especie la tendencia a juzgar los comportamientos morales?

Pero hay más. Cabe sostener que el rastreo de universales éticos no termina en nuestra naturaleza como agentes morales. De alguna manera, existen también universales que se refieren no a las motivaciones en esta ocasión sino a los criterios.

Además, lo que los neurocientíficos denominan de "plasticidad" - término que designa "la capacidad general de la neurona y de sus sinapsis para cambiar de propiedades en función de su estado de actividad" (Changeux, 2004), es decir, la aptitud del cerebro para cambiar a la luz de una experiencia que puede modificar las conexiones neuronales e inscribirse en la red neuronal constituye la clave de la naturaleza humana en todos los niveles, desde el cerebro y la mente hasta las sociedades y los valores morales. De hecho, la gran ventaja evolutiva del ser humano radica en su capacidad para escapar a las limitaciones (al "determinismo") de la evolución. Somos libres, en ese sentido, no a pesar de la naturaleza, mas gracias a ella.

\section{El sentimiento moral}

El planteamiento de Darwin al aplicar a la evolución humana sus principios de la selección natural incluye extensos comentarios acerca del tipo de ser que ésta habría modelado respecto a los instintos sociales y al comportamiento ético. Las páginas del Descent of Man (Darwin, 1871) nos parecen hoy un tanto sesgadas por la ideología victoriana como, por ejemplo, cuando habla de la condición casi pre-humana de los indios fueguinos. Conviene recordar que Darwin no contó con una teoría de la herencia adecuada y que, mediante el 
mecanismo de la pangénesis, siguió de cerca los esquemas lamarckianos de herencia de los caracteres adquiridos. De tal suerte, Darwin creía que un comportamiento más civilizado de los pueblos primitivos los convertiría con el paso del tiempo, por selección natural, en seres humanos de una naturaleza igual a la de los británicos. Como se ve, tampoco Darwin se libró de un inadecuado diagnóstico antropológico a la hora de considerar la dignidad humana. Pero la descripción implícita que hace de los instintos sociales es adecuada para situar el contenido naturalista del comportamiento moral.

Como hemos dicho antes, Darwin utiliza el concepto del moral sense, que tiene una larga historia en la filosofía anglosajona. Shaftesbury, Hutcheson y Hume consideraron el moral sense como una fuerza innata ligada a la simpatía que lleva a cada persona a actuar en favor de los otros. El comportamiento moral sería, pues, una especie de suma algebraica de fuerzas gravitacionales - de inequívoca referencia a Newton- gracias a la cual un sentimiento moral centrípeto se combinaría con el instinto egoísta centrífugo para dar ese mundo de equilibrios precarios que es tanto la naturaleza como la sociedad humana.

Darwin podría ser tenido por el último autor de esa tradición intelectual que procede de la llustración escocesa pero, en su obra, el moral sense adquiere un carácter más general. En el Descent of Man se dice que cualquier animal con bien marcados instintos sociales como puedan ser los afectos paternofiliales, "would inevitably acquire a moral sense or conscience, as soon as its intellectual powers had become as well, or nearly as well developed, as in man." (Darwin, 1871). Se trata de una cuestión hipotética: ningún animal ha alcanzado el nivel de las facultades mentales humanas. Pero si lo lograse, entonces también adquiriría el mismo nivel de moral sense que nosotros.

He aquí, pues, descrita la idea darwiniana acerca de la condición moral humana: afectos simpáticos, por una parte, propios de un animal de vida social, y unas facultades intelectuales altas que permiten evaluar los riesgos y las consecuencias de nuestras acciones. El conjunto da el moral sense. Y éste permite alcanzar el grado de la conducta ética. Es ése el fundamento naturalista de la dignidad humana.

Gracias al moral sense, damos el carácter de actos heroicos a acciones como la de salvar la vida de otra persona poniendo en riesgo la nuestra. En el Descent of Man se incluyen referencias a actos parecidos que llevan a cabo otros primates como los babuinos. Pero Darwin concluye que no son actos morales porque los monos no cuentan con la capacidad de entender la consecuencia de sus acciones: se comportan así por instinto, mediante una determinación genética fuerte. Pero nosotros observamos, anticipamos, meditamos y evaluamos. Llevamos a cabo no sólo conductas morales sino juicios morales de las conductas ajenas. Se trata de un conjunto en el que es difícil establecer la frontera entre los afectos simpáticos y los cálculos evaluativos pero es probable que, en buena medida, la evolución de nuestro cerebro se debiera a la necesidad de llevar a cabo esas complicadísimas operaciones que permiten entender la relación social, el papel de cada uno y la conducta que cabe esperar de cada miembro del grupo. Nicholas Humphrey (Humphrey, 1976) sostiene que otros simios como los chimpancés cuentan también con ese "pensamiento maquiavélico". Súmese la evaluación ética, y tenemos el moral sense. 
El comportamiento moral humano, que incluye, por cierto, la atribución de dignidad a las personas, tiene por tanto como componente esencial -aunque no único- un complejo esquema de evaluación y anticipación de las conductas ajenas. Una "teoría de la mente" de los otros.

Como recuerda Pinker (2002), todo el mundo tiene una teoría implícita sobre la naturaleza humana. Todos nos afanamos en prever el comportamiento de los demás, lo que significa que todos necesitamos entender qué es lo que mueve a las personas a adoptar determinadas conductas. Se trata de la perspectiva de los "sistemas intencionales" que propuso Dennett (1971), en la que los humanos somos considerados como sujetos intencionales de tercer orden: contamos con una teoría de la mente del otro en la que se incluye el que ese otro sujeto también tiene una teoría de mi propia mente, y sabe que yo la tengo respecto de él. Así, las acciones encaminadas a lograr mis deseos en la vida social se ajustarán a lo que mi teoría de la mente del compañero o el contrincante incluye acerca de la mente ajena. Es una situación parecida a la de un juego de ajedrez en el que mi adversario me ofrece un gambito, un sacrificio en principio absurdo que va a beneficiarme. ¿Por qué lo hace? ¿Me beneficia en realidad o se trata de que yo crea que me beneficia cuando va a perjudicarme? Aunque puede que me beneficie, sí, pero el otro intenta que yo sospeche que no es así y rechace el gambito... La cadena del "yo creo-que tú crees-que yo creo-que tú crees" puede extenderse indefinidamente. Los mejores jugadores de ajedrez son los que, ya sea por intuición o por reflexión, pueden llevarla más lejos.

La teoría de la mente del otro es una teoría tácita de la naturaleza humana, que procede de la experiencia que tenemos acerca de nosotros mismos. Veamos en qué consiste por lo que hace a la evaluación de las acciones ajenas.

Se trata de un conjunto en el que intervienen deseos, creencias y acciones. Atribuimos a los demás un comportamiento que obedece a los objetivos que mantienen - los deseos - y a la visión del mundo de que disponen —las creencias- para deducir las acciones que cabe prever que llevarán a cabo. Como ha mostrado Antoni Doménech (Doménech, 2002), en el sistema cualquiera de los tres componentes - deseos, creencias y acciones- puede ser deducido en función de los otros dos. Si conocemos (o intuimos) los deseos de alguien y sus creencias, estamos en condiciones de predecir su conducta. Pero si contemplamos su conducta, y sabemos sus creencias, deduciremos cuáles son sus objetivos; así en todos los casos. Es cierto que para que la ecuación funcione es preciso dar por garantizada una condición especial de la naturaleza humana: en qué medida estamos dispuestos a alcanzar lo que son nuestros deseos. La idea central de la teoría darwiniana de la selección natural establece que cada organismo maximiza sus intereses propios -identificados en ese caso con la obtención de la progenie. Pues bien, el comportamiento altruista parece escapar a esa regla. Quienes actúan en beneficio de otro emplean sus recursos para favorecer la adaptación ajena, no la propia. ¿Cómo pudo fijarse por selección natural un comportamiento así?

Ni Darwin ni los neodarwinistas pudieron explicarlo. La sociobiología logró hacerlo a través de modelos como los de la selección de grupo (WynneEdwards, 1962) y de parentesco (Hamilton, 1964). Es dudosa la aplicación de esos modelos al caso humano (vid, por ejemplo, Cela-Conde \& Ayala, 2004) pero a lo que íbamos es a la manera particular como los miembros de nuestra 
especie satisfacen sus deseos. ¿Mediante una maximización de los intereses personales?

Es éste el terreno en el que aparece la conexión más profunda entre naturaleza humana y comportamiento moral, esa misma que buscamos para ofrecer una fundamentación naturalista de la dignidad. Si nos remontamos también, como hacíamos antes, a la época griega, los humanos nos atribuimos la condición de seres racionales. Somos, pues, preferidores racionales, dispuestos a maximizar nuestros intereses de acuerdo con nuestras creencias. ¿O no es así?

\section{La aparición de los universales: el sentido de la justicia}

La idea de universales morales junto con la de selección natural lévanos a las posibles explicaciones biológicas de dichos universales, lo que es generalmente considerado como un nuevo tipo de ética evolucionista, el tipo de ética que sostiene que los instintos morales han surgido por evolución (Stamos, 2009). Por ejemplo, la teoría de juegos, la neurociencia cognitiva y la primatología nos han proporcionado ya los primeros indicios acerca de si esa idea de la naturaleza humana como propia de un preferidor racional es acertada.

La intuición acerca de nuestro comportamiento racional ha fundamentado buena parte de los estudios tanto científicos como humanísticos acerca del ser humano, incluyendo la mayor parte de la economía neoclásica. Pero fenómenos como el del castigo altruista ponen en duda la premisa de nuestra racionalidad perfecta.

El castigo altruista (Fehr \& Gächter, 2002) es un comportamiento en el que un sujeto $A$, al ver cómo otro $B$ se salta las reglas de la convivencia, está dispuesto a poner algo de su parte con tal de que el trasgresor B sea castigado pese a que su "delito" no afecte a A de manera personal. El castigador altruista no recibe ningún beneficio pero sí sufre una pérdida - de bienes o de cualquier otro tipo- , así que una maximización de sus intereses impediría que aceptase tal pérdida. La teoría de juegos ha estudiado a fondo los posibles modelos de castigo altruista —mediante el juego del ultimátum, por ejemplo . Pero también sabemos algo acerca de la manera como otros primates se comportan en este dominio. Los monos capuchinos son, al igual que los humano, castigadores altruistas (Brosnan \& De Waal, 2003). Los chimpancés, no; se comportan como preferidores racionales (Jensen, Call, \& Tomasello, 2007).

Eso significa al menos dos cosas. La primera, que nuestro grupo hermano, el linaje animal más cercano evolutivamente a nosotros, difiere en ese aspecto. La segunda, que no sabemos cuál pudo ser el rasgo fijado antes. O bien el linaje común a capuchinos + chimpancés + humanos tiene como rasgos primitivo el del castigo altruista, con los chimpancés desarrollando una apomorfia de preferencia racional, o bien el rasgo primitivo es esta racionalidad firme, con lo que los comportamientos de castigo altruista de capuchinos y humanos son homoplasias, rasgos fijados de manera independiente.

La diferencia es importante porque, de la mano del castigo altruista, lo que aparece en realidad es el sentido de la justicia. Si estamos dispuestos a 
sacrificar una parte de nuestro patrimonio con tal de que la equidad se imponga, eso significa que nuestros instintos sociales contienen esa particular manera de sentirnos bien. Es ese sentido de la justicia el que subyace a la idea de John Rawls (Rawls, 1975) acerca de la capacidad para lograr compromisos por medio del velo de ignorancia, planteando en términos de justicia universal y no de intereses particulares las reglas del juego. Ese lazo ha sido mencionado por Nicholas Humphrey (Humphrey, 2006) en un volumen en el que científicos de diversa extracción analizan el fenómeno de la justicia. Por más que resulte imposible sintetizar siquiera aquí su contenido, se trata de un ejemplo de las posibilidades que brinda la naturalización de los valores humanos.

Puede que, a estas alturas, la idea antropológica de lo que es un ser humano haya alcanzado una universalidad superior a la griega clásica, a la escolástica y a la ilustrada pero ¿no existen ya fronteras que ampliar? Claro que las hay. Las dudas acerca de la dignidad no se detienen en la consideración de los ciudadanos-promedio. Sin olvidar que, con nuestras leyes y nuestras conductas, podemos estar manteniendo todavía la calificación de cuasipersonas (¿un nuevo "Compromiso de las 3/5 partes"?), por ejemplo, para la mayoría de los homosexuales que continúan la lucha contra una injustificada desigualdad de derechos. Las fronteras siguen abiertas. ¿Mantienen su dignidad los delincuentes convictos, los psicópatas, los genocidas? ¿Debe concederse a los embriones? ¿Y a partir de qué momento? ¿Tienen dignidad los chimpancés? ¿Y los monos verdes, que usan la semántica para advertir de la presencia de un predador? Más allá de los primates, ¿la tienen los mamíferos, las aves, los peces? ¿También las cucarachas, las amebas y las bacterias?

La apuesta menos arriesgada consiste en basarse en el conocimiento científico, en las evidencias que vayan obteniéndose desde el funcionamiento del cerebro humano al carácter del ecosistema, para acotar y definir la dignidad, y en la misma medida, rechazar toda y cualquier forma de abstraccionismo puramente teorizante en lo que se refiere a la definición de la dignidad. ¿Será siempre una tarea reservada, con exclusividad, a la actividad filosófica humana?

Desde un punto de vista evolucionista, es tentador ver las principais teorías éticas normativas - la ética aristotélica de la virtud, el egoísmo psicológico de Hobbes, el utilitarismo de Bentham y Mill, las deontologías de Kant y de Ross, el velo de ignorancia de Rawls, e incluso, más recientemente, la ética medioambiental y la ética feminista - más o menos del mismo modo en que John Hick (1985) ve las principales religiones del mundo: cada una de las principales religiones del mundo es como un indio ciego en la parábola budista de los ciegos y el elefante, en la que cada uno de los indios ciegos toca y describe una parte diferente del cuerpo de un elefante y cada uno de ellos confunde la parte con el todo. (Stamos, 2009)

Dado que los humanos y las instituciones morales humanas evolucionaron durante millones de años en la compleja dinámica grupal de los cazadoresrecolectores, puede muy bien ser que cada una de las principales teorías normativas sea como uno de esos indios ciegos que describen y atribuyen una realidad completa a solamente una parte del todo de la ética normativa tal como evolucionó en los humanos. De tal modo, dar la espalda a las 
justificaciones naturalistas es, sin más, un riesgo que no podemos permitirnos, por no decir un disparate.

\section{Principios y valores jurídicos: naturaleza humana, libertad y dignidad}

Si se acepta la necesidad de un cambio de paradigma, parece razonable sostener que toda forma jurídica operativa destinada a evaluar el problema de la dignidad humana bajo la perspectiva "naturalista" debería empezar por una pregunta: ¿En qué medida los planteamientos acerca de la relación que existe entre naturaleza y dignidad humana podrán arrojar luz sobre como concebimos los derechos humanos? Es decir, ¿en qué medida es posible y útil la plasmación jurídica de la concepción naturalista de la dignidad humana en el contexto de los Derechos Humanos?

La idea de que la dignidad se asienta en nuestra biología va contra las creencias jurídicas habituales y a menudo entra en conflicto con las directrices dictadas por la ley, la moral o la religión. En ningún ámbito ha tenido eso más importancia que en el de la bioética y, en especial, dentro de algunas de las recientes batallas en relación con el libre albedrío, la igualdad, la eutanasia y el aborto. Sin embargo, parece haber una evidente preocupación por parte de los derechos humanos en el sentido de eliminar el funcionamiento de esa dinámica conflictiva, favoreciendo la libertad y la autonomía del individuo. Por ejemplo, entre los objetivos de la Declaración Universal sobre Bioética y Derechos Humanos figura el de "proporcionar un marco universal de principios y procedimientos" destinados, a partir de un "dialogo multidisciplinario", a "promover el respeto de la dignidad humana y proteger los derechos humanos, velando por el respeto de la vida de los seres humanos y las libertades fundamentales, de conformidad con el derecho internacional relativo a los derechos humanos".

Se establece, así, una evidente conexión entre principios, normas y valores jurídicos: no parece razonable concebir la dignidad humana sin libertad, autonomía, igualdad y pluralismo jurídico, y esos valores, a su vez, resultarían inútiles si no redundasen en favor de la dignidad humana. Los principios inspiradores de los derechos humanos constituyen su propio fundamento y, como tal, configuran y delimitan su propio sentido en todo el proceso, tanto el de la elaboración normativa como el de su aplicación práctico-concreta. Esos principios son los parámetros condicionantes y vinculantes para la interpretación y aplicación de derecho y, al mismo tiempo, un límite para el orden jurídico interno de los Estados.

También como principio fundamental, el concepto de la dignidad humana va más allá de la mera funcionalidad normativa. La idea de la libre constitución y el pleno desarrollo del individuo bajo el manto de instituciones justas (igualitaria y fraterna) se caracteriza por ser un elemento axiológico objetivo de carácter indisponible. Junto con los derechos inviolables que le son inherentes, el respeto a la ley y los derechos de los demás, constituye el fundamento último del orden jurídico-político internacional. La dignidad de la persona humana, por tanto, no es una simple idea valorativa (lo mejor) en el modelo normativo, sino que expresa uno de los criterios condicionantes del orden establecido. Su 
colocación en la Declaración como principio normativo (lo debido) le da un significado en especial relevante como elemento universal fundamental, inviolable e indisponible $y$, en consecuencia, como un criterio axiológiconormativo, vinculante e irrevocable de la praxis judicial.

Pero a pesar de ese cuidadoso diseño, la concepción dominante de los derechos humanos contiene a nuestro entender un vicio de origen que lastra sus posibles resultados: el del énfasis en el individuo como criterio esencial. Y esta circunstancia dirige el pensamiento a las siguientes cuestiones: ¿qué debemos hacer con la dignidad humana? ¿Por qué mientras la naturaleza humana, tal como aparece hoy en día a la luz de los descubrimientos científicos, propone como algo evidente a nuestra consideración una nueva idea de transformación, nos recusamos tenaz e taxativamente a rechazar la sensación de que nada se transforma? ¿Por qué entonces, si está claro que no puede haber, en adelante, aproximación filosófica, ética, jurídica, etc., que no pase por un análisis detallado de la naturaleza humana, tenemos, no obstante, insistido por seguir un camino contrario a una integración interdisciplinar necesaria que, a toda evidencia, seguramente contribuirá más para la comprensión de aquello que nos hace humanos y dignos, en el palco de la naturaleza y de la cultura? ¿Por qué se insiste en situar el problema de la dignidad en función del hombre singular, encerrado en su esfera individual y exclusivamente moral? ¿Continúa siendo razonable concebir un concepto de la dignidad humana que pretenda ser digno de crédito en la actualidad manteniéndolo al margen de un modelo darwiniano acerca de la naturaleza humana? (vid., por ejemplo, Malabou, 2007).

No parece ni razonable, ni oportuno. La cristalización de una existencia individual, separada y autónoma - digna, por tanto- es un elemento mucho más complejo y gradual que la simple y obvia asunción del principio de la dignidad como mera directriz normativa. La caracterización de la dignidad humana que hemos desarrollado a lo largo de este artículo nos lleva a admitir que tenemos buenas razones para suponer como correcta la afirmación de que no cabe inferir gran cosa acerca de la dignidad humana a partir de enunciados meramente lógico-formales, religiosos, normativos, de ideales políticos o de vagas elucubraciones o especulaciones académico-filosóficas. La investigación de la dignidad está vinculada de forma estrecha a la noción de la naturaleza humana, que, a su vez, es una cuestión tan fáctica como la medida del perihelio de Mercurio (Mosterín, 2006). Resulta, por tanto, epistémicamente insostenible la postura de los que postulan una dignidad de cierto tipo con independencia de cualquier información empírica sobre la naturaleza humana o como simple condición transcendental de posibilidad de la moralidad, de la responsabilidad, de la libertad...

Y la idea de nuestra naturaleza que se deriva de la concepción biológica del ser humano parte de la situación básica de relación que existe entre cada uno de los seres humanos con otros seres humanos. La naturaleza humana ni se agota ni queda bien descrita en función del individuo moral singular, encerrado en su esfera individual, que ha servido hasta ahora para caracterizar como valor básico la construcción del Estado liberal. Hoy sabemos que lo que denominamos naturaleza humana tiene cualidades y predisposiciones físicas y morales innatas. Sabemos que algunas propiedades fijas de la mente son innatas, que todos los seres humanos poseen ciertas destrezas y habilidades 
de las que carecen otros animales, y que ese conjunto de rasgos conforman la condición humana. Sabemos, más allá de toda duda razonable, que somos el resultado del proceso evolutivo que, para bien o para mal, ha moldeado nuestra especie. Y el resultado es una especie interdependiente, ética y social.

De hecho, la idea misma de la libertad - condicio sine qua non en la que se arraigan la autonomía y la dignidad humana - no se puede concebir al margen de la relación con otras personas, porque la forma de ser del hombre en el mundo es de por sí una forma de ser interpersonal. La autonomía de ser y de hacer está inscrita en la misma esencia del hombre; de ella surge la posibilidad y capacidad de actuar de manera libre y digna. Pues bien, esa autonomía no puede tener lugar más que en el diálogo y la interacción con otros (con el "otro"). Dicho de otro modo, no hay libertad humana que no se plasme en la capacidad de sentir la llamada del otro. No existe una libertad lograda y completa que luego, de forma posterior y secundaria, se vea revestida de una dimensión ética. Dimensión libre y dimensión ética son los mismos, y también es ésa una constatación que cobra su sentido a la luz del naturalismo.

Darwin presento el "hombre moral" basándose en que su capacidad cognitiva para comprender, evaluar y elegir complementa el moral sense para dar lugar a la naturaleza humana evolucionada. Nada de eso es posible en una situación de aislamiento. La más íntima esencia y la medida de la libertad en el ser humano son la posibilidad y la capacidad para sentir la llamada del otro y responder a ella. Desde el momento en que el otro aparece como un otro libre y autónomo, nace también la dimensión ético-jurídica, relacional e intersubjetiva de la dignidad.

\section{La autonomía personal}

Dado que los humanos no nos creamos a nosotros mismos en un sentido absoluto, tiene que haber algo en nosotros de lo que no somos la causa. Pero el problema central con respecto a nuestro interés por la libertad y la dignidad humana no estriba en cuáles de los acontecimientos en nuestra vida volitiva están determinados causalmente por condiciones externas a nosotros. Lo que en verdad cuenta, en aquello concerniente a la libertad y la dignidad, no es la independencia causal. Es la autonomía. Y la autonomía es en esencia una cuestión acerca de si somos activos o pasivos en nuestros motivos y elecciones; de si, con independencia del modo en que los adquirimos, son motivos y elecciones que realmente queremos y que, por tanto, no son ajenos a nosotros (Frankfurt, 2004). El sujeto autónomo, en tanto que sujeto libre, no se encuentra ni por debajo ni por encima del sujeto de carne y hueso (genes, mente y cerebro) y tampoco requiere, para salvar la libertad y la dignidad, de un "agente moral autónomo" como alternativa a una explicación causal en términos biológicos y evolutivos. Ser fiel a la naturaleza no es, por tanto, recusar en su nombre a la libertad (elemento constitutivo de la dignidad y, a su vez, efecto de la naturaleza); nuestros cerebros plásticos realmente están diseñados para producir libertad y autonomía (Ansermet \& Magistretti, 2004). Para la perspectiva naturalista, ser fiel a ella consiste en extender este gesto a la categoría de principios fundamentales para los derechos humanos. 
Es ese sentido relacional de dignidad humana el que debe estar anclado en un derecho destinado a favorecer la libertad y la autonomía de la persona. No se trata de un problema de poca importancia, de un mero ejercicio mental para los filósofos académicos y juristas. La elección del modo de abordar el problema de la dignidad humana supone un importante y gran diferencia en la forma en que nos vemos a nosotros mismos como especie. Por añadidura, establece una medida tanto para la legitimidad y la autoridad del derecho como de los enunciados normativos. Determina, en última instancia, la dirección y el sentido del discurso jurídico y político.

Desde esta perspectiva, el interés humano por la dignidad como valor prioritario en el orden de los valores viene a convertirse, desde la idea de la libertad humana, en una invitación a vivir de forma genuinamente humana nuestra existencia a partir del reconocimiento del "otro". De hecho, la responsabilidad por los demás, que emana de su mera existencia, es una dimensión necesaria para la autodeterminación de la autonomía, la libertad y la dignidad humana. El fundamento del derecho no está en la dignidad abstracta, sino en el plasticidad concreta de nuestro cerebro, genéticamente programado para la libertad y la vida en sociedad (Ansermet \& Magistretti, 2004). Lejos de ser un principio contrario o separado a nuestra naturaleza, es ésta, nuestra naturaleza, la que da sentido a nuestra idea de la dignidad humana.

\section{Por un nuevo modelo de derecho: normativa y aplicación}

La idea de dignidad fundada en una teoría fuerte de la naturaleza humana nos lleva a adoptar como premisa un modelo de derecho sostenido, entre otras cosas, en la moral de respeto mutuo. Somos nosotros mismos los que otorgamos derechos morales a todo hombre, por más que busquemos sus fundamentos en instancias trascendentes al ser humano como puedan ser un ente sobrenatural, la selección natural o la Historia. No existen, pues, derechos que no sean otorgados para resolver problemas adaptativos relacionados con nosotros mismos.

En el caso del principio de la dignidad, la asignación de la calidad de ser digno de algo - que implica tener en cuenta las necesidades, deseos y creencias de los demás - tiene por objeto garantizar las condiciones mínimas de una vida satisfactoria y plena, que es, en verdad, el bien mayor que podemos esperar. En eso reside, de hecho, la dimensión intersubjetiva, relacional o coexistencial de la dignidad humana: actuar bajo el supuesto implícito de significados otorgados y compartidos en un conjunto de acciones coordinadas de conductas recíprocas.

En consecuencia, parece que la mejor manera para explicar, comprender y aplicar el principio de la dignidad es a partir de la idea del ser humano en su triple configuración: a) en su existencia individual, separada y autónoma (y, por tanto, principio del derecho); b) como fin de su mundo ( $\mathrm{y}$, como tal, también del derecho); y c) como sujeto de vínculos sociales elementales a través de los cuales construye, a partir de las reacciones de los demás, los estilos aprobados de una vida socio-comunitaria digna de ser vivida en su plenitud (es decir, 
como titular de derechos y deberes que proyectan en la colectividad su existencia como ciudadano).

El objetivo esencial en una operación así, recuerda Chomsky (2006), debe ser siempre el de intentar crear la visión de una sociedad donde impere la justicia. Eso significa crear una teoría social basada, si es posible, en una concepción humanista y firme de la naturaleza humana, —o, si se quiere, de la esencia humana-, es decir, intentar establecer las conexiones entre un concepto de la naturaleza humana que dé lugar a la libertad, la dignidad, la creatividad y otras características humanas fundamentales, y una noción de estructura social donde estas propiedades pueden realizarse para que la vida humana adquiera un sentido pleno.

Pero el principio de la dignidad no sólo tiene importancia en el proceso políticolegislativo de elaboración de un diseño normativo. También, y muy en especial, en el momento tan problemático como concreto de su aplicación. En ese sentido, la primacía que desempeña el principio de la dignidad humana como un criterio clave de las normas, valores y principios contenidos en el orden jurídico se convierte en garantía contra un peligroso relativismo moral, ya proceda del iusnaturalismo transcendental o del positivismo jurídico. A menudo los jueces deben tomar decisiones en función de intereses arbitrarios, o de una injustificada interferencia del Estado o de cualquier otro agente social. Tales decisiones conducen al sacrificio de derechos de todo punto inalienables, que son los que habilitan la existencia de los ciudadanos como individuos plenamente libres. Para evitarlo, un sistema axiológico-normativo fundado en la dignidad humana debe exigir que las normas, tanto internacionales como internas de cada Estado, sean interpretadas y aplicadas de un modo que no choquen con los valores y principios superiores. La práctica jurídica ha de servir para promover su efectiva realización, es decir, de que ese es el papel que cabe al operador del derecho a partir de una praxis social e hermenéutica comprometida con una concepción robusta de la naturaleza humana - es decir, que la noción de derecho humano indica precisamente que el hombre no se convierte en miembro de la sociedad humana mediante una captación realizada sobre la base exclusiva de determinadas normas, principios o valores socioculturales sino en virtud de su pertenencia biológica a la especie Homo sapiens.

A titulo de resumen, los derechos humanos constituyen un instrumental normativo muy útil para dar cauce a una mediación pragmático-normativa de aplicación de las leyes que sea eficaz para evitar que el individuo quede interferido en su plano vital por los demás agentes sociales. Pero como condición necesaria para que suceda eso, para poder huir de las imposiciones arbitrarias, la propia actividad hermenéutica de los derechos humanos debe ser formulada a partir de una posición antropológica capaz de explicar la fenomenología de la acción humana. Sólo desde el punto de vista del ser humano y de su naturaleza le será posible al juez captar el sentido y la función del principio de la dignidad humana como unidad de un contexto vital, ético y cultural.

En realidad no se trata de pretender imponer grandes novedades. Lo que se intenta mediante la concepción naturalista de los valores humanos es vincular de forma prioritaria la concepción de la dignidad humana a las virtudes ilustradas de libertad, igualdad y fraternidad. Esas tres virtudes, que componen 
el contenido de la justicia, sólo son diferentes aspectos de la misma actitud humanista fundamental destinada a garantizar el respeto sin condiciones de la dignidad humana. No se puede realizar en la práctica el principio de la dignidad de la persona si éste no se materializa en las condiciones de vida de cada ciudadano, garantizándole libertad e igualdad de oportunidades en una sociedad fraterna y decente (Margalit, 2010).

Es sabido que la norma jurídica, cualquiera que sea su grado de imperatividad, debe promover la justicia. El modo más decisivo de hacerlo es garantizar de forma incondicional la libertad, la igualdad y la autonomía del ser humano que, en su conjunto, configuran su dignidad. Nada de eso habría resultado posible, ni lo sería nunca, si la naturaleza humana no hubiese adquirido a través del camino de nuestra evolución las bases necesarias para alcanzar la dignidad, entenderla y hacer de ella el sentido mismo de nuestra existencia como primates peculiares.

\section{Bibliografía}

Ayala, F. J. (1987). The Biological Roots of Morality. Biology \& Philosophy, 2, 235-252.

Brosnan, S., \& De Waal, F. (2003). Monkeys reject unequeal pay. Nature, 425, 297-299.

Cela Conde, C. J. (1985). De genes, dioses y tiranos. Madrid: Alianza Editorial.

Cela-Conde, C. J., \& Ayala, F. J. (2004). Evolution of Morality. In F. M. Wuketits \& C. Antweiler (Eds.), Handbook of Evolution Vol.1: The Evolution of Human Societies and Cultures (pp. 171-189). Weinheim (Germany): John Wiley \& Sons.

Changeux, J.-P.(2004). The physiology of Truth. Neuroscience and human knowledge, Cambridge, MA: Belknap, Harvard University Press.

Chomsky, N. (1966). Cartesian Linguistics. New York, NY: Harper \& Row.

Chomsky, N. (1968). Language and Mind (Ed. castellana, El lenguaje y el entendimiento. Barcelna: Seix barral, 1971 ed.). New York, NY: Harcourt, Brace, \& World.

Chomsky, N. (1980). Rules and Representations. Oxford: Blackwell.

Chomsky, N. (1985). Knowledge of Language. New York, NY: Praeger.

Chomsky, N. \& Foucault, M. (2006). La naturaleza humana: justicia versus poder, Buenos Aires: Katz Editores

Darwin, C. (1871). The Descent of Man, and Selection in Relation to Sex. London: John Murray.

Dennett, D. C. (1971). Intentional Systems. Journal of Philosophy, 8, 87-106.

Doménech, A. (2002). Algunos enigmas de la racionalidad económica. In J. E. García-Albea (Ed.), Llenguatge, Ciència i Societat, homenaje a Noam Chomsky. Tarragona: Universitat Rovira i Virgili.

Fehr, E., \& Gächter, S. (2002). Altruistic punishment in humans. Nature, 415, 137-140. 
Frankfurt, H. G. (2004). The Reasons of Love, NJ, Princeton: Princeton University Press

Hamilton, W. D. (1964). The Genetical Evolution of Social Behavior. Journal of Theoretical Biology, 7, 1-52.

Hare, R. M. (1979). What Makes Choices Rational? Review of Metaphysics, 32, 623-637.

Hauser, M. D. (2006). Moral minds. How nature designed our universal sense of right and wrong. New York, NY: HarperCollins Publishers

Humphrey, N. (2006). Introduction: science looks at fairness. Social Research, 73, 345-348.

Humphrey, N. K. (1976). The social function of intellect. In P. P. G. Bateson \& R. A. Hinde (Eds.), Growing Points in Ethology (En R. Byrne y A. Whiten (eds.) (1988), Machiavellian Intelligence, pp. 13-26 ed., pp. 303-317). Cambridge: Cambridge University Press.

Jensen, K., Call, J., \& Tomasello, M. (2007). Chimpanzees Are Rational Maximizers in an Ultimatum Game. Science, 318, 107-109.

Kant, I. (1785). Grundlegung zur Metaphysik der Sitten. Riga: Johann Friedrich Hartknoch.

Magistretti, P. \& Ansermet, F. (2004). À chacun son cerveau. Plasticité neuronale et inconscient. Paris: Odile Jacob

Malabou, C. (2007). ¿Qué hacer con nuestro cerebro?, Madrid: Tiempo al Tiempo

Margalit, A. (2010). La sociedad decente, Barcelona: Paidós.

Mosterín, J. (2006). La naturaleza humana. Madrid: Editorial Espasa Calpe S.A. Muguerza, J. (1977). La razón sin esperanza. Madrid: Taurus.

Rawls, J. (1975). A Theory of Justice. Cambridge, MA: Harvard University Press.

Singer, P. (1981). The Expanding Circle. New York, NY: Farrar, Strauss \& Giroux.

Stamos, D.N. (2009). Evolución. Los grandes temas: sexo, raza, feminismo, religión y otras cuestiones, Madrid: Biblioteca Buridán

Tugendhat, E. (1979). La pretensión absoluta de la moral y la experiencia histórica. In U. N. d. E. a. Distancia (Ed.), Actas de las 1as. jornadas de Etica e Historia de la Ciencia. Madrid: UNED.

Wilson, E. O. (1975). Sociobiology: The New Synthesis (Hay ed. castellana ed.). Cambridge, MA: Harvard University Press.

Wilson, E. O. (1978). On Human Nature. Cambridge, MA: Harvard University Press.

Wynne-Edwards, V. C. (1962). Animal Dispersion in Relation to Social Behaviour. Edinburgh: Oliver and Boyd.

Zeki, S. (1993). A Vision of the Brain. Oxford: Blackwell. 